\title{
What Do Patient-Centered Medical Home (PCMH) Teams Need to Improve Care for Primary Care Patients with Complex Needs?
}

\author{
Susan E. Stockdale, $P h D^{1,2}$, Marian L. Katz, $P h D^{7}$, Alicia A. Bergman, $P h D^{7}$, \\ Donna M. Zulman, MD, MPH, ${ }^{3,4}$, Angela Denietolis, MD $D^{5}$, and Evelyn T. Chang, \\ $M D, M S H S^{1,6,7}$
}

\begin{abstract}
'VA HSR\&D Center for the Study of Healthcare Innovation, Implementation, and Policy, VA Greater Los Angeles Healthcare System, Sepulveda, CA, USA; ${ }^{2}$ Department of Psychiatry and Biobehavioral Sciences, University of California, Los Angeles, CA, USA; ${ }^{3}$ Center for Innovation to Implementation, VA Palo Alto Healthcare System, Menlo Park, CA, USA; ${ }^{4}$ Department of Medicine, Stanford University, Stanford, CA, USA; 5 VA Office of Primary Care, Washington D.C., USA; ${ }^{\circ}$ VA Greater Los Angeles Healthcare System, Division of General Internal Medicine, Los Angeles, CA, USA; ${ }^{7}$ Department of Medicine, David Geffen School of Medicine, University of California, Los Angeles, CA, USA.
\end{abstract}

\begin{abstract}
:
BACKGROUND: Intensive primary care (IPC) programs for patients with complex needs do not generate cost savings in most settings. Strengthening existing patientcentered medical homes (PCMH) to address the needs of these patients in primary care is a potential high-value alternative.

OBJECTIVES: Explore PCMH team functioning and characteristics that may impact their ability to perform IPC tasks; identify the IPC components that could be incorporated into $\mathrm{PCMH}$ teams' workflow; and identify additional resources, trainings, and staff needed to better manage patients with complex needs in primary care.
\end{abstract}

METHODS: We interviewed 44 primary care leaders, PCMH team members (providers, nurses, social workers), and IPC program leaders at 5 VA IPC sites and analyzed a priori themes using a matrix analysis approach.

RESULTS: Higher-functioning PCMH teams were described as already performing most IPC tasks, including panel management and care coordination. All sites reported that $\mathrm{PCMH}$ teams had the knowledge and skills to perform IPC tasks, but not with the same intensity as specialized IPC teams. Home visits/assessments and co-attending appointments were perceived as not feasible to perform. Key stakeholders identified 6 categories of supports and capabilities that PCMH teams would need to better manage complex patients, with care coordination/ management and fully staffed teams as the most frequently mentioned. Many thought that $\mathrm{PCMH}$ teams could make better use of existing VA and non-VA resources, but might need training in identifying and using those resources.

CONCLUSIONS: PCMH teams can potentially offer certain clinic-based services associated with IPC programs, but tasks that are time intensive or require physical absence from clinic might require collaboration with community service providers and better use of internal and external healthcare system resources. Future studies

Supplementary Information The online version contains supplementaru material available at httos://doi.ora/10.1007/s 11606-020-06563-x.

Published online January 28, 2021 should explore the feasibility of PCMH adoption of IPC tasks and the impact on patient outcomes.

KEY WORDS: patient-centered medical home; intensive primary care; qualitative interviews.

J Gen Intern Med 36(9):2717-23

DOI: $10.1007 / \mathrm{s} 11606-020-06563-\mathrm{x}$

(C) This is a U.S. government work and not under copyright protection in the U.S.; foreign copyright protection may apply 2021

\section{BACKGROUND}

Despite their growing popularity, some research shows that intensive primary care (IPC) programs for patients with complex needs may not generate cost savings. ${ }^{1-4}$ IPC programs vary in terms of patient population targeted, services provided, care team composition, and care delivery mode, but generally aim to improve care and reduce costs for the most complex, resource-intensive patients. ${ }^{5,6}$ Typical program components include intensive case management by interdisciplinary teams, comprehensive assessments, home visits, care transition management, pharmaceutical services, health coaching, advanced care planning, and caregiver support. ${ }^{7,8}$ Evidence for IPC program effectiveness for lowering inappropriate acute care utilization and improving quality is mixed. ${ }^{9-13}$ Given the varied evidence for IPC cost savings and effectiveness, healthcare systems may be reluctant to invest in new, resourceintensive programs to improve care for these patients.

Providing enhanced resources and training to existing primary care teams, such as patient-centered medical homes (PCMH), to better manage these patients may be a less costly alternative to investing in IPC programs. PCMH aims to provide patient-centered, comprehensive team-based care that is coordinated across the healthcare system and with links to community social services, improving access, quality, and patient experience. ${ }^{14}$ Although PCMH teams vary in composition and roles performed by team members, ${ }^{15}$ they have many of the key features described in literature on successful 
IPC programs, including multidisciplinary teams with care managers trained in disease management. ${ }^{9,16,17}$ Furthermore, literature supports trusted relationships with care managers and other clinicians to improve health outcomes among complex patients. ${ }^{18}$ Although PCMH teams may include a case manager with the skills to address patients with complex needs, ${ }^{19,20}$ they may lack the knowledge, communication tools and processes necessary for intensive care management, ${ }^{21}$ and sufficient resources for a dedicated case manager for these patients. ${ }^{9,21}$ Additionally, with higher caseloads and less flexibility of time and team member roles, PCMH teams may have limited ability to perform some IPC program tasks. $^{22}$ PCMH teams may also experience difficulty with adding IPC tasks that require clinic workflow changes, new staff roles, ${ }^{23}$ and integrating care managers. ${ }^{21}$

No studies thus far have described which IPC tasks could feasibly be performed by PCMH teams and what PCMH teams would need to perform these tasks. In this study, we analyzed qualitative interviews with PCMH team members, IPC program leaders, and facility primary care (PC) leaders at five Veterans Health Administration (VA) facilities with IPC programs to (1) explore how $\mathrm{PCMH}$ team functioning may impact their ability to perform IPC tasks, (2) identify which IPC tasks could be incorporated into PCMH teams' workflow, and (3) identify additional resources, trainings, and staff PCMH teams would need to better manage their patients with complex needs.

\section{METHODS}

For this study, we used qualitative data from semi-structured interviews with PCMH team members (PCPs, RNs, and social workers), facility PC leaders, and IPC program leaders. All authors of this manuscript attest that the activities that resulted in this manuscript were not conducted as part of a research project, but as part of a non-research evaluation conducted under the authority of the VA Office of Primary Care. Due to the agreement with participants that only the evaluation team would have access to their audio recordings and transcripts, only paraphrased or summarized data are available upon request from the first author.

\section{Setting}

Introduced in 2010, VA's PCMH model, called Patient Aligned Care Teams (PACT), emphasized continuity through teambased care, improved access, care management and coordination, and patient-centered communication. ${ }^{24}$ The "teamlet" staffing model includes one full-time equivalent each of a primary care provider (PCP), registered nurse $(\mathrm{RN})$, licensed practical nurse (LPN), and clerk per continuity panel of 1200 patients. VA's PCMH also includes social workers, behavioral health providers, pharmacists, health coaches, and other extended team members to support several core "teamlets." 24 Implementation has been variable, ${ }^{25}$ with some evidence indicating an association between greater fidelity to $\mathrm{PCMH}$ core components and better chronic disease management outcomes. ${ }^{19}$

\section{PACT Intensive Management Program}

Data are from the evaluation of the PACT Intensive Management (PIM) demonstration, which has been described in detail elsewhere. ${ }^{8,26}$ PIM was a VA five-site IPC demonstration in 2015-2018. The IPC models at four sites augmented PCMH with an interdisciplinary IPC team, while the fifth site replaced PCMH with the IPC team for participating patients. Team composition varied, but generally included a part-time physician lead, full-time $\mathrm{RN}$ and/or nurse practitioner (NP), social worker, and mental health provider. Components included chronic disease management, comprehensive patient assessment and evaluation, care and case management, transitional care support, preventive home visits, pharmaceutical services (including medication management), chronic disease self-management, caregiver support services, health coaching, and advanced care planning. ${ }^{8}$ PCMH teams at these sites may also have performed chronic disease management and self-management, care/case management, pharmaceutical services, and health coaching, but with lower intensity.

\section{Sampling and Recruitment}

We used stratified quota sampling to select PCMH team members by role, sampling from a list of PCMH teams with IPC patients, with a target quota of two PCPs, two RNs, and one social worker per site. We also selected 2-4 facility-level and mid-level PC leaders to participate based on a list of $\mathrm{PC}$ and nursing leaders that were involved in IPC program implementation (from study administrative records or nominated by IPC program leaders). For one IPC site with more than 4 identified PC leaders, we randomly selected 4 leaders. We interviewed all IPC program leaders, most of whom were also facility or midlevel PC leaders and were known from study records and their participation in the evaluation. We emailed the initial invitation to participants, followed by a telephone call approximately 3-5 days later, and after that instant messaging, with a maximum of 3 follow-up attempts.

\section{Data Collection}

Participants were interviewed by telephone in 2017 (PCMH team members) and 2018 (PC and IPC leaders). Interviews were approximately 20-30 $\mathrm{min}$ (to minimize clinical disruption) for PCMH team members and 60-90 min for PC and IPC program leaders. Interviews were audio-recorded and professionally transcribed. We asked participants to describe PCMH team functioning at their sites, which IPC tasks PCMH teams could feasibly perform, and what resources, trainings, or staffing PCMH teams would need to better manage their patients with complex needs. Question wording varied slightly 
Table 1 Key Stakeholder Sample and Response Rate

\begin{tabular}{|c|c|c|c|c|c|c|}
\hline & Total & $\begin{array}{l}\text { PCMH } \\
\text { PCP }\end{array}$ & $\begin{array}{l}\text { PCMH } \\
\text { RN }\end{array}$ & $\begin{array}{l}\text { PCMH } \\
\text { SW }\end{array}$ & $\begin{array}{l}\text { PC } \\
\text { leaders }\end{array}$ & $\begin{array}{l}\text { IPC } \\
\text { leaders }\end{array}$ \\
\hline Invited to participate & 56 & 16 & 14 & 5 & 15 & 6 \\
\hline Ineligible & 1 & 0 & 1 & 0 & 0 & 0 \\
\hline Refused/no response & 9 & 8 & 0 & 0 & 1 & 0 \\
\hline Unable to contact & 2 & 0 & 2 & 0 & 0 & 0 \\
\hline Completed interview & 44 & 8 & 11 & 5 & 14 & 6 \\
\hline $\begin{array}{l}\text { Response rate (complete/(invited - ineligible + unable to } \\
\text { contact)) }\end{array}$ & $83 \%$ & $50.0 \%$ & $92 \%$ & $100 \%$ & $93 \%$ & $100 \%$ \\
\hline
\end{tabular}

depending on key stakeholder group corresponding with their roles and relationships with the IPC team (see Supplemental Table 1). The response rate was $83 \%$ (Table 1).

\section{Analysis}

We used Atlas.ti ${ }^{27}$ to code and analyze the qualitative interview data. The lead author developed an initial codebook based on the interview guide and preliminary data analysis for formative feedback to pilot sites. A second analyst and the lead author tested and revised the codebook definitions by coding 3 interviews each, comparing and discussing coding. The lead author then coded all the interviews, and the second analyst reviewed the coding.

We analyzed the data to summarize key stakeholders' perspectives of 3 main a priori themes determined by the interview topics: How do key stakeholders' perceptions of PCMH team functioning at their site shape their views of PCMH teams' ability to perform intensive primary care? Which components of IPC programs would be feasible for PCMH teams to perform? What tools, resources, and training would $\mathrm{PMCH}$ teams need to improve care management for their most complex patients? We generated Atlas.ti reports for the codes pertaining to these three themes. We used these reports with a matrix analysis approach to compare experiences across sites and key stakeholders. ${ }^{28}$ Specifically, an analyst abstracted or paraphrased quotes from the code reports into an Excel spreadsheet, which were then checked against the original transcripts by a different analyst. Within the 3 main themes, the lead author summarized common subthemes described across all sites and key stakeholder groups, which a second analyst then reviewed and confirmed. We compared responses between stakeholder groups (PCMH members, facility leaders, and IPC program leaders) and sites, but found no clear differences by group or site. While rare, any disagreements among analysts about codes, coding applications, and derivation of subthemes were resolved through discussion. ${ }^{29}$

\section{RESULTS}

Table 1 shows the distribution of participants by key stakeholder role. Study key stakeholders felt that PCMH teams may be able to perform most clinic-based IPC tasks; however, team functioning would influence their ability to perform IPC tasks.
Time-intensive tasks or tasks requiring physical absence from clinic were perceived as less feasible. Key stakeholders also identified six categories of supports or capabilities PCMH teams need to perform IPC tasks.

\section{Team Functioning May Impact PCMH Teams' Ability to Perform IPC Tasks}

Some key stakeholders linked the ability to perform IPC tasks with team functioning, as characterized by key stakeholders in Table 2. As one PC leader described:

"High functioning [PCMH] teams huddle. They communicate well. They delegate tasks well. They are aware of all the other things that can be done, other avenues, referrals, what all the different services do....present [themselves] to the patient as a team and not as individuals who happen to work together."

Several key stakeholders across sites noted that staffing shortages contributed to the inability to work at "top of license" and perform panel management and care coordination tasks.

Table 2 Descriptions of High-Functioning and Low-Functioning PCMH Teams

\begin{tabular}{|c|c|c|}
\hline $\begin{array}{l}\text { High-functioning } \\
\text { (ratings of 9-10 on } \\
\text { 10-point scale) }\end{array}$ & $\begin{array}{l}\text {-Strong patient } \\
\text { advocates } \\
\text {-Team helps break } \\
\text { down barriers for } \\
\text { patients } \\
\text {-Conflict resolution } \\
\text { - Relationship building } \\
\text {-Adequately staffed for } \\
\text { clinic demands } \\
\text { - Nurses performing } \\
\text { panel management and } \\
\text { care coordination } \\
\text {-Team members } \\
\text { valuing, respecting, } \\
\text { supporting each other }\end{array}$ & $\begin{array}{l}\text { - Collaborative teams } \\
\text { - Huddle and } \\
\text { communicate well } \\
\text { with team members } \\
\text {-Delegate tasks } \\
\text { - Present themselves } \\
\text { as a team to the } \\
\text { patient } \\
\text {-Nurses call patients } \\
\text { re: appointment } \\
\text { reminders }\end{array}$ \\
\hline $\begin{array}{l}\text { Moderate- and } \\
\text { lower-functioning } \\
\text { (ratings of 6-8) }\end{array}$ & $\begin{array}{l}\text {-Staffing shortages } \\
\text { - Challenges with panel } \\
\text { management and care } \\
\text { coordination } \\
\text {-Team requires } \\
\text { training in mental } \\
\text { health and behavioral } \\
\text { issues }\end{array}$ & $\begin{array}{l}\text { - Competing tasks } \\
\text {-Staff unable to work } \\
\text { at top of license } \\
\text {-Nurses not } \\
\text { co-located with pro- } \\
\text { viders } \\
\text {-Team requires } \\
\text { training in PCMH } \\
\text { principles }\end{array}$ \\
\hline
\end{tabular}


PCMH Teams May Be Able to Perform Most Clinic-Based IPC Tasks, but Time-Intensive Tasks or Tasks Requiring Physical Absence from Clinic Were Perceived as Less Feasible

Many key stakeholders thought that PCMH teams were already doing all or most IPC tasks, or could perform most clinic-based aspects of IPC. Several mentioned that with much larger panels than IPC teams, PCMH teams could not provide the same level of intensity or availability (e.g., less frequent check-ins/calls with patients, not being able to call patients back right away). As one RN described:

"I already do many of these things with my patients ... We do engagement, advocacy, etc., but I can't always be the navigator for someone who needs this level of intensity. I can't follow-up with the patients, unless the patients are proactive (responds, picks up the phone, follows up, initiates contact)."

Table 3 contains a list of specific IPC tasks mentioned as feasible and not feasible for PCMH teams to perform. A few key stakeholders did not think that PCMH teams could perform time-intensive or time-sensitive IPC tasks, such as creating individualized care plans, intensive chart review/assessment, quick responses to phone calls, engaging families/caregivers, engaging hard-to-reach patients such as those who are homeless or cognitively impaired, and identifying community resources. Tasks requiring physical absence from clinic (e.g., home visits and accompanying patients to visits

Table 3 Key Stakeholder Perspectives of IPC Tasks that PCMH Teams Could Perform

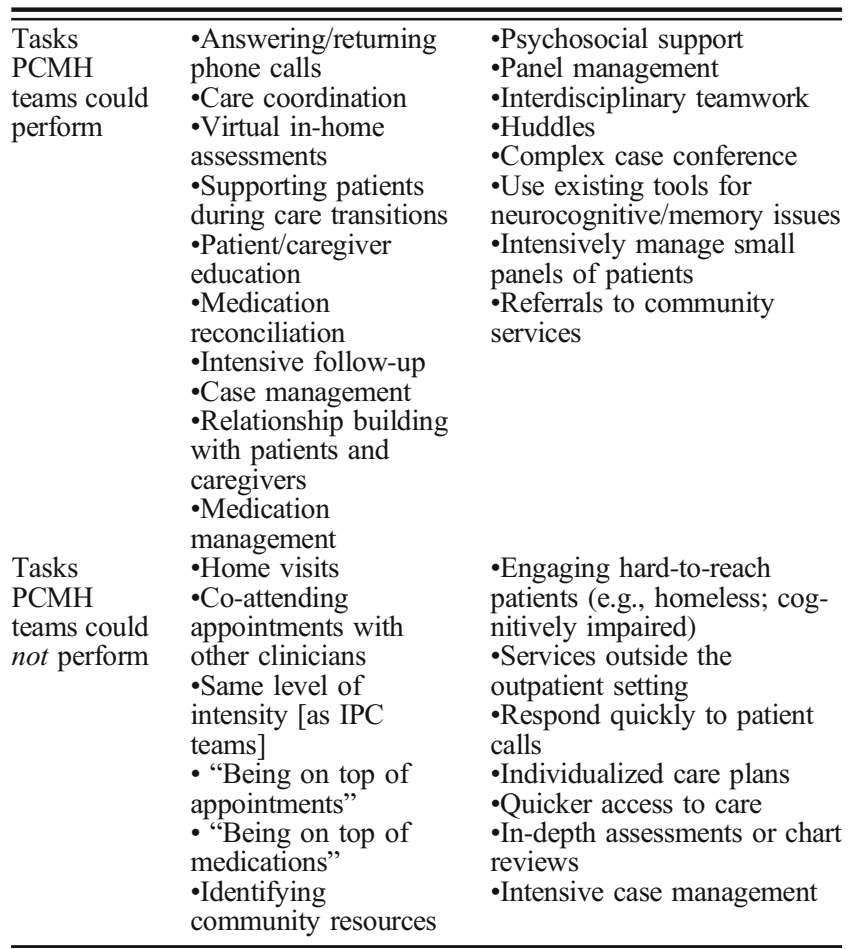

with other healthcare providers) were perceived as not feasible. As one social worker said, "the home visits are so helpful but I just can't imagine a way that the $[\mathrm{PCMH}]$ social worker could be gone the whole day, or the $[\mathrm{PCMH}] \mathrm{RN} . "$

Some key stakeholders gave examples of how PCMH teams could perform specific IPC tasks. For example, they could collaborate more closely with integrated mental health and the PCMH social workers for patients with intense psychosocial needs, and with home-based primary care and pharmacy for medication management. In addition, the team huddle could be used as an expanded interdisciplinary team meeting or mini-case conference by inviting social work, pharmacy, and behavioral health to discuss specific patients. Virtual in-home assessments could be performed by PCMH RN care managers or social workers with VA's newly enhanced videovisit capabilities.

\section{Six Categories of Supports or Capabilities PCMH Teams Need to Perform IPC Tasks}

Key stakeholders identified six categories of supports or capabilities that PCMH teams would need to provide better care for patients with complex needs: (1) fully staffed PCMH teams or additional staffing; (2) RN-led panel management and care coordination; (3) training; (4) better use of existing resources (VA and non-VA), (5) additional specific resources or services; and (6) more time or smaller panels (see Table 4).

A majority said that PCMH teams would need full staffing (PCP, RN care manager, LPN, and clerk as well as behavioral health, pharmacy, and other ancillary services) or additional staff. Some also indicated that providers and staff working at "top of license" and who are flexible and willing to work with this population were needed:

"We would need $[\mathrm{PCMH}]$ team members that were willing to go above and beyond. I just happen to have [PCMH] team members that will do anything. We would need willing participants to do this kind of more intensive management." (PCMH PCP)

Many key stakeholders identified better panel management and care coordination performed by RNs and supports for those tasks as important for caring for patients with complex needs. PCMH staffing shortages and not working at top of license contribute to less than optimal panel management and care coordination, as one PC nurse leader described:

"We just went over the chronic care management guidelines that [Office of Nursing Services] sent out and I think our RNs do very little of that because 
Table 4 Supports or Capabilities Key Stakeholders Thought PCMH Teams Would Need to Perform IPC Tasks

\begin{tabular}{|c|c|c|}
\hline $\begin{array}{l}\text { Fully staffed } \\
\text { PCMH teams/ } \\
\text { additional staff- } \\
\text { ing }\end{array}$ & $\begin{array}{l}\text { - Fully staffed teams } \\
\text {-Stable teams } \\
\text { - More staff } \\
\text {-Providers } \\
\text { - Nurse practitioners } \\
\text { - Registered nurses } \\
\text {-Social workers } \\
\text {-Specialized teams } \\
\text { - Case managers } \\
\text {-Inpatient nurse } \\
\text { practitioners for care } \\
\text { transitions/discharge } \\
\text { planning } \\
\text { - "Staff who are flexible" } \\
\text { "Willing to do the } \\
\text { work" }\end{array}$ & $\begin{array}{l}\text {-Specialists/ } \\
\text { technicians in } \\
\text { homelessness, } \\
\text { substance abuse } \\
\text { • Staff (intermediate } \\
\text { care technicians, } \\
\text { social workers, } \\
\text { psychologists) for } \\
\text { co-attending appoint- } \\
\text { ments with other } \\
\text { clinicians } \\
\text { •Peer support for } \\
\text { navigation } \\
\text {-Psychologist } \\
\text { •Providers and staff } \\
\text { practicing at top of } \\
\text { license } \\
\text { •Facilitator to help } \\
\text { teams with data on } \\
\text { their patients }\end{array}$ \\
\hline $\begin{array}{l}\text { Panel } \\
\text { management/ } \\
\text { care coordina- } \\
\text { tion }\end{array}$ & $\begin{array}{l}\text {-Individual patient } \\
\text { data/measures/goals } \\
\text { •Expectation [from } \\
\text { leaders] that PCMH } \\
\text { teams will do care } \\
\text { coordination } \\
\text {-More frequent } \\
\text { monitoring and follow-up }\end{array}$ & $\begin{array}{l}\text {-Interdisciplinary team } \\
\text { meetings } \\
\text {-Dedicated time for } \\
\text { panel management, } \\
\text { care coordination, } \\
\text { team meetings } \\
\text {-Better care } \\
\text { coordination with } \\
\text { community }\end{array}$ \\
\hline Training & $\begin{array}{l}\text {-PCMH roles and } \\
\text { responsibilities } \\
\text {-Panel management } \\
\text {-Treatment and } \\
\text { engagement methods for } \\
\text { complex patients }\end{array}$ & $\begin{array}{l}\text {-Available resources, } \\
\text { including community } \\
\text {-Boundary setting } \\
\text { with patients } \\
\text {-Personality disorders }\end{array}$ \\
\hline $\begin{array}{l}\text { Better use of } \\
\text { existing } \\
\text { resources (VA } \\
\text { and non-VA) }\end{array}$ & $\begin{array}{l}\text { - Data and performance } \\
\text { measures for panel } \\
\text { management } \\
\text {-Space utilization }\end{array}$ & $\begin{array}{l}\text {-Available tools and } \\
\text { resources in VA and } \\
\text { community settings }\end{array}$ \\
\hline $\begin{array}{l}\text { Additional } \\
\text { specific } \\
\text { resources/ } \\
\text { services/ } \\
\text { capacities }\end{array}$ & $\begin{array}{l}\text {-Flexibility to meet } \\
\text { patients outside the office } \\
\text { setting } \\
\text { - Someone to drive } \\
\text { patients to appointments } \\
\text {-Expanded telehealth } \\
\text { capacity/telehealth RNs } \\
\text {-Ability to offer } \\
\text { same-day appointments }\end{array}$ & $\begin{array}{l}\text {-Ability to do home } \\
\text { visits or use } \\
\text { community resources } \\
\text { for home safety } \\
\text { evaluation } \\
\text {-Ability to transfer } \\
\text { calls from specific } \\
\text { patients directly to } \\
\text { PCMH teams (e.g., } \\
\text { not routed through a } \\
\text { call center) }\end{array}$ \\
\hline $\begin{array}{l}\text { More time/ } \\
\text { smaller panels }\end{array}$ & $\begin{array}{l}\text {-Smaller panels } \\
\text {-More time }\end{array}$ & $\begin{array}{l}\text {-More efficient } \\
\text { workflows }\end{array}$ \\
\hline
\end{tabular}

they're so busy doing everyone else's job. Then the PCPs are doing everybody else's job, too."

Many key stakeholders also thought PCMH teams could use existing care management tools and resources but would need more training in identifying and using them. As one PC lead physician expressed, “... to get the tools disseminated to everybody and to teach everybody how to use it - I need a trainer here that will work with all of the teams."

\section{DISCUSSION}

This qualitative evaluation using interviews with PCMH team members and IPC and PC leaders suggests that PCMH teams characterized as "well-staffed" and/or high-functioning are able to incorporate key panel management and care coordination strategies for patients with complex needs. Most key stakeholders thought that PCMH teams had the knowledge and skills to perform IPC tasks, but home visits/assessments and co-attending appointments with patients were perceived as not feasible for them to perform. A few key stakeholders thought IPC tasks could be performed by PMCH teams but with less intensity and using existing resources. Our key stakeholders also identified 6 categories of supports or capabilities that PCMH teams would need to better manage care for their patients with complex needs, with fully staffed PCMH teams and better panel management and care coordination as the most frequently mentioned. Many thought that $\mathrm{PCMH}$ teams could make better use of existing VA and non-VA resources and services, but would need more training in identifying and using resources specific to this patient population.

Our results confirm and expand on literature regarding barriers and facilitators to successfully managing patients with complex needs in primary care. Barriers to implementing care coordination for these patients - a key IPC task-are well documented in the literature and include misaligned financial incentives, ${ }^{9,23,30-32}$ lack of information and communication systems ${ }^{21}$ and lack of appropriate data and decision-making tools. ${ }^{23,32,33}$ These barriers were not identified by our key stakeholders as impediments, and may be less common in VA because it is a large integrated healthcare system with two important features of successful IPC programs ${ }^{16,34}$-a well-established electronic health record (EHR) that facilitates communication among VA healthcare team members and data for identifying complex patients for panel management. ${ }^{35}$

Successful IPC programs usually consist of teams centered around a care manager and include social workers and behavioral health. ${ }^{16}$ VA's PCMH model similarly centers around an $\mathrm{RN}$ care manager, equipped with dashboards and other care management tools embedded in the EHR. ${ }^{24}$ VA's PCMH also includes social workers and behavioral health providers to assist with care management for patients with complex needs. A majority of key stakeholders in our study emphasized the importance of RNs performing care coordination and care management and full staffing for PCMH teams to perform IPC tasks. As has been found in previous studies, ${ }^{17,31} \mathrm{a}$ few of our key stakeholders also mentioned the importance of role flexibility and staff that are willing to perform IPC tasks, suggesting that some adaptations to standardized PCMH roles could enhance the team's ability to care for patients with complex needs. Other recent studies suggest that clinical pharmacy specialists, who are also included in VA's PCMH as extended team members, could also play a bigger role in care management by performing medication reconciliation, taking over chronic disease management of complex patients, and performing other care coordination tasks. ${ }^{36-38}$

Our results suggest that PCMH teams in large integrated healthcare systems may be well suited to perform IPC tasks that overlap with tasks they already perform, but may not be 
able to take on the additional workload needed to intensively manage these patients. With full staffing and additional training in use of existing resources (such as panel management tools within the EHR and community resources for various patient needs), PCMH teams might be a more cost-effective approach to managing patients with complex needs, but more research is necessary to establish this. Other essential nonclinic-based IPC tasks, such as home visits and safety assessments, may be possible with better use of and collaboration with community programs and services. ${ }^{17,31}$ The VA has recently implemented several virtual care modalities which are beginning to expand access for all patients to primary care and specialty providers. ${ }^{39}$ Virtual modalities might facilitate more frequent follow-up with patients with complex needs and could be used for virtual home visits. In addition, implementation of the MISSION Act might facilitate increased collaboration between VA and community services that could improve care for these patients (such as home visit services). ${ }^{17}$ These resources could also improve primary care teams' ability to manage their workload and free up more time to focus on patients with complex needs.

Our study had some limitations. The study was conducted within five VA facilities, and the results may not be applicable to other healthcare systems or all VA facilities, but may be relevant to other large, integrated healthcare systems with EHR and team-based primary care. Key stakeholders varied in terms of how much interaction they had with IPC teams, and those with less interaction may have less knowledge of IPC components and what services IPC teams provided for patients. Our semi-structured interviews did not systematically ask key stakeholders about whether specific IPC components could be provided by PCMH teams, and thus, we cannot draw any conclusions based on the frequency with which specific components were mentioned. Our data also do not permit investigation of the association between IPC task performance and patient outcomes, and thus, we cannot draw any conclusions about which IPC tasks are most important for improving care for patients with complex needs.

These limitations are balanced by several study strengths. This is the first study to explore qualitatively which IPC components PCMH teams could feasibly perform and what additional supports, resources, or training they might need to improve care for patients with complex needs. Our rich qualitative data provided specific examples of how PCMH teams might perform some IPC tasks with available staffing and resources, and suggested interventions to provide IPC in PCMH settings (for example, collaboration with community services to provide home visits or conducting virtual home visits).

\section{CONCLUSIONS}

Use of existing PCMH teams to perform clinic-based IPC tasks for patients with complex needs may be a less costly alternative to establishing separate IPC programs in primary care. PCMH teams, however, need staff with the time and ability to perform these tasks, and training in use of existing tools and resources to optimally manage patients with complex needs. PCMH teams are less well suited for IPC services such as home visits and co-attending appointments, but these services could be provided through collaboration with community service providers and better use of internal and external healthcare system resources. Future studies should explore the feasibility of PCMH adoption of IPC tasks and the impact on patient outcomes.

Supplementary Information The online version contains supplementary material available at https://doi.org/10.1007/s11606-02006563- $x$.

Acknowledgments: Contributors: The authors would like to acknowledge Emily Wong, MPH, for assistance with coding qualitative interview data; Steven M. Asch, MD, MPH, and Jeffrey E. Rollman for reviewing and commenting on previous versions of the manuscript; and Michelle Wong, $\mathrm{PhD}$, Tana Luger, $\mathrm{PhD}$, and Karleen Giannitrapani, PhD, for feedback on the "RESULTS" section. Funders: This study was conducted as part of the PACT Intensive Management evaluation, funded by VA Office of Primary Care, XVA 65-054. The views expressed in this article are those of the authors and do not necessarily reflect the position or policy of the Department of Veterans Affairs, or the US government, or other affiliated institutions. Prior presentations: VA HSRD/BUERI Research Meeting, Washington, D.C., 2019; Society for General Internal Medicine Annual Meeting, Washington, D.C., 2019; AcademyHealth Annual Research Meeting, Washington, D.C., 2019.

Corresponding Author: Susan E. Stockdale, PhD; Department of Psychiatry and Biobehavioral Sciences, University of California, Los Angeles, CA, USA (e-mail: Susan.Stockdale@va.gov).

\section{Compliance with Ethical Standards:}

Conflict of Interest: The authors declare that they do not have a conflict of interest.

\section{REFERENCES}

1. McWilliams JM, Schwartz AL. Focusing on high-cost patients - the key to addressing high costs? N Engl J Med. 2017;376(9):807-809.

2. Peikes D, Anglin G, Dale S, et al. Evaluation of the comprehensive primary care initiative: fourth annual report. Mathematica Policy Research;2018.

3. Swanson J, Weissert WG. Case managers for high-risk, high-cost patients as agents and street-level bureaucrats. Med Care Res Rev. 2018;75(5):527-561.

4. Finkelstein A, Zhou A, Taubman S, Doyle J. Health care hotspotting - a randomized controlled trial, $N$ Engl $J$ Med. 2020;382(2):152-162.

5. Edwards ST, Peterson $\mathbf{K}$, Chan B, Anderson J, Helfand M. Effectiveness of intensive primary care interventions: a systematic review. $J$ Gen Intern Med. 2017;32(12):1377-1386.

6. Yee T, Lechner A, Carrier E. High-intensity primary care: lessons for physician and patient engagement. National Institute for Health Care Reform. 2012;9:1-7.

7. Boult C, Green AF, Boult LB, Pacala JT, Snyder C, Leff B. Successful models of comprehensive care for older adults with chronic conditions: evidence for the Institute of Medicine's "retooling for an aging America" report. J Am Geriatr Soc. 2009;57(12):2328-2337.

8. Chang ET, Raja PV, Stockdale SE, et al. What are the key elements for implementing intensive primary care? A multisite Veterans Health Administration case study. Paper presented at: Healthcare2018. 
9. Bodenheimer T, Berry-Millett $\mathbf{R}$. Care management of patients with complex health care needs. Princeton, NJ: Robert Wood Johnson Foundation;2009. 19.

10. de Bruin SR, Versnel $\mathbf{N}$, Lemmens LC, et al. Comprehensive care programs for patients with multiple chronic conditions: a systematic literature review. Health policy. 2012;107(2-3):108-145.

11. McCarthy D, Ryan J, Klein S. Models of care for high-need, high-cost patients: an evidence synthesis. Issue Brief(Commonw Fund). 2015;31:1-19.

12. Smith SM, Soubhi H, Fortin M, Hudon C, O'Dowd T. Managing patients with multimorbidity: systematic review of interventions in primary care and community settings. Bmj. 2012;345:e5205.

13. Stokes J, Panagioti M, Alam R, Checkland K, Cheraghi-Sohi S, Bower P. Effectiveness of case management for 'at risk' patients in primary care: a systematic review and meta-analysis. PLoS One. 2015;10(7):e0132340.

14. Lipson D, Rich E, Libersky J, Parchman M. Ensuring that patientcentered medical homes effectively serve patients with complex health needs. In. Rockville, MD: Agency for Healthcare Research and Quality; 2011

15. Veet CA, Radomski TR, D'Avella C, et al. Impact of healthcare delivery system type on clinical, utilization, and cost outcomes of patient-centered medical homes: a systematic review. J Gen Intern Med. 2020;35(4):1276 1284 .

16. Hong C, Siegel A, Ferris T. Caring for high-need, high-cost patients: what makes for a successful care management program? New York, NY2014.

17. Hudon C, Chouinard MC, Lambert M, Diadiou F, Bouliane D, Beaudin J. Key factors of case management interventions for frequent users of healthcare services: a thematic analysis review. BMJ Open. 2017;7(10):e017762.

18. Hudon C, Chouinard MC, Aubrey-Bassler K, et al. Case management in primary care for frequent users of health care services: a realist synthesis. Ann Fam Med. 2020;18(3):218-226.

19. Rosland AM, Wong E, Maciejewski M, et al. Patient-centered medical home implementation and improved chronic disease quality: a longitudinal observational study. Health Serv Res. 2018;53(4):2503-2522.

20. Zulman DM, Pal Chee C, Ezeji-Okoye SC, et al. Effect of an intensive outpatient program to augment primary care for high-need veterans affairs patients: a randomized clinical trial. JAMA Intern Med. 2017; 177(2): 166-175.

21. Dorr DA, Wilcox A, Burns L, Brunker CP, Narus SP, Clayton PD Implementing a multidisease chronic care model in primary care using people and technology. Dis Manag. 2006;9(1):1-15.

22. Breland JY, Asch SM, Slightam C, Wong A, Zulman DM. Key ingredients for implementing intensive outpatient programs within patient-centered medical homes: a literature review and qualitative analysis. Healthc (Amst). 2016;4(1):22-29.

23. Blumenthal D, Chernof B, Fulmer T, Lumpkin J, Selberg J. Caring for high-need, high-cost patients - an urgent priority. $N$ Engl $J \mathrm{Med}$. 2016;375(10):909-911.

24. Rosland A, Nelson K, Sun $\mathbf{H}$, et al. The patient-centered medical home in the Veterans Health Administration. American Journal of Managed Care. 2013; 19(7):e263-272.
25. Nelson KM, Helfrich $\mathbf{C}$, Sun $\mathbf{H}$, et al. Implementation of the patientcentered medical home in the Veterans Health Administration: associations with patient satisfaction, quality of care, staff burnout, and hospital and emergency department use. JAMA Intern Med. 2014;174(8):13501358.

26. Chang ET, Zulman DM, Asch SM, et al. An operations-partnered evaluation of care redesign for high-risk patients in the Veterans Health Administration (VHA): study protocol for the PACT Intensive Management (PIM) randomized quality improvement evaluation. Contemp Clin Trials. 2018;69:65-75.

27. Atlas.ti 8 Windows User Manual [computer program]. Berlin, Germany: Scientific Software Development GmbH; 2018.

28. Averill J. Matrix analysis as a complementary analytic strategy in qualitative inquiry. Qualitative Health Research. 2002; 12(6):855-866.

29. Miles MB, Huberman AM. Qualitative Data Analysis: an Expanded Sourcebook. Thousand Oaks, CA: Sage; 1994.

30. Hayes SL, Salzberg CA, McCarthy D, et al. High-need, high-cost patients: who are they and how do they use health care? A populationbased comparison of demographics, health care use, and expenditures. Issue Brief (Commonw Fund). 2016;26:1-14.

31. Hasselman D. Super-Utilizer Summit: common themes from innovative complex care management programs. Hamilton, NJ: Center for Health Care Strategies. 2013;2013:1-37.

32. Tinetti ME, Fried TR, Boyd CM. Designing health care for the most common chronic condition-multimorbidity. JAMA. 2012;307(23):24932494.

33. Long P, Abrams M, Milstein A, Anderson G, Apton KL, Dahlberg $\mathbf{M}$. Effective care for high-need patients. Washington, DC. 2017.

34. Bodenheimer T. Strategies to reduce costs and improve care for highutilizing Medicaid patients: reflections on pioneering programs. Center for Health Care Strategies, Inc. 2013.

35. Kizer KW, Demakis JG, Feussner JR. Reinventing VA health care: systematizing quality improvement and quality innovation. Med Care. 2000;38(6 Suppl 1):17-16.

36. McFarland MS, Lamb K, Hughes J, Thomas A, Gatwood J, Hathaway $\mathbf{J}$. Perceptions of integration of the clinical pharmacist into the patient care medical home model. J Healthc Qual. 2018;40(5):265-273.

37. Nigro S, Garwood C, Berlie $\mathbf{H}$, et al. Clinical pharmacists as key members of the patient-centered medical home: an opinion statement of the Ambulatory Care Practice and Research Network of the American College of Clinical Pharmacy. Pharmacotherapy. 2014;34:96-108.

38. Scott MA, Hitch B, Ray L, Colvin G. Integration of pharmacists into a patient-centered medical home. J Am Pharm Assoc (2003). 2011;51(2):161-166.

39. Affairs UDoV. Connected care. https://connectedcare.va.gov/. Published 2020. Accessed March 12, 2020.

Publisher's Note: Springer Nature remains neutral with regard to jurisdictional claims in published maps and institutional affiliations. 